\title{
Zoneamento da cultura de cana-de-açúcar (Saccharum spp.) no Município de Suzanápolis, SP
}

\author{
ZONING of sugarcane (Saccharum spp.) IN THE MUNICIPALITY OF SUZANÁPOLIS, \\ $S P$
}

ZONIFICACIÓN de la caña de azúcar (Saccharum spp.) EN EL MUNICIPIO DE

SUZANAPOLIS, SP

\author{
Patricia Helena Mirandola Garcia ${ }^{1}$ \\ João Marcos Bertelli Franco ${ }^{2}$ \\ Helio Ricardo Silva ${ }^{3}$
}

Recebido em 04/2017 - aceito em 07/2017.

\begin{abstract}
RESUMO: A cultura da cana-de-açúcar no Estado de São Paulo está se expandindo cada vez mais, buscando atender a demanda por açúcar e etanol. Sendo assim, nas áreas nas quais são cultivadas tradicionalmente, como na região de Ribeirão Preto, $\mathrm{SP}$, o potencial de expansão para o seu cultivo está diminuindo, fato que aumenta a procura por terras. Atualmente, as questões ambientais no Brasil vêm destacando-se em busca de preservar o meio ambiente em relação às queimadas de cana-de-açúcar e à conservação das Áreas de Preservação Permanentes (APPs). Para a prática de colheita mecanizada, a declividade máxima que é viável às colhedoras do mercado é de $12 \%$. A escolha do município de Suzanápolis, SP, justifica-se pelo fato dessa região apresentar baixa rentabilidade agrícola e ser coberta praticamente por pastagens. Com isso, o presente trabalho teve como objetivos, por meio de sensoriamento remoto, de geoprocessamento e do software SPRING ${ }^{\circledR} / I N P E$, identificar as áreas com a cultura da cana-de-açúcar de acordo com classes de declividade, avaliando o potencial de expansão dessa cultura na região e de áreas aptas à mecanização. Buscou-se, também, avaliar o nível de conservação da rede de drenagem e verificar se há cultivo de cana-de-açúcar em Áreas de Preservação Permanente.
\end{abstract}

Palavras-chave: Cana-de-açúcar; Áreas de Preservação Permanente; Questões ambientais.

ABSTRACT: The culture of sugar cane in the State of São Paulo is expanding more and more, seeking to meet the demand for sugar and ethanol. Therefore, in the areas in which they are grown traditionally, as in the region of Ribeirão Preto, $S P$, the expansion potential for your cultivation is decreasing, which increases the demand for land.Currently, environmental issues in Brazil come especially in seeking to preserve the environment in relation to the burning of sugar cane and the conservation of areas of Permanent Preservation (APPs).For mechanized harvesting, the maximum slope that is viable to market harvesters is $12 \%$. The choice of the municipality of Suzanápolis, SP, is justified by the fact that region present low profitability agriculture and be practically covered by pastures. With that, the present work had as objectives, by means of remote sensing, GIS and software SPRING®/INPE, identify areas with the culture of sugarcane according to slope classes, evaluating the potential for expansion of this culture in the region and areas suitable for mechanization. Sought to also 
assess the conservation level of the drainage network and check for cultivation of sugar cane in Permanent preservation areas.

Keywords: sugarcane; Permanent preservation areas; Environmental issues

RESUMEN: El cultivo de caña de azúcar en el estado de São Paulo está ampliando cada vez más, buscando satisfacer la demanda de azúcar y etanol. Por lo tanto, en las áreas en las que se cultivan tradicionalmente, como en la región de Ribeirão Preto, $S P$, la expansión potencial para su cultivo está disminuyendo, lo que aumenta la demanda de tierras. En la actualidad, temas ambientales en Brasil vienen sobre todo en la búsqueda de preservar el medio ambiente en relación con la quema de caña de azúcar y la conservación de áreas de preservación permanente (APP). Para la cosecha mecanizada, la pendiente máxima que es viable para cosechadoras de mercado es del 12\%. La elección del municipio de Suzanápolis, SP, es justificada por el hecho de que agricultura región de la baja rentabilidad actual y prácticamente cubierto por pastos. Con eso, el presente trabajo tuvo como objetivos, mediante teledetección, SIG y software primavera® / INPE, identificar las áreas con el cultivo de caña de azúcar según las clases de pendiente, evaluando el potencial para la expansión de esta cultura en la región y zonas aptas para la mecanización. Intentó también evaluar el nivel de conservación de la red de drenaje y compruebe para el cultivo de caña de azúcar en áreas de preservación permanente.

Palabras clave: caña de azúcar; Áreas de preservación permanente; Cuestiones ambientales.

\section{INTRODUÇÃO}

As imagens de satélites são ferramentas indispensáveis para o monitoramento agrícola e ambiental, principalmente por apresentarem dados georreferenciados de baixo custo e boa exatidão em um curto prazo de tempo. Esse sistema auxilia, por exemplo, no acompanhamento e no desenvolvimento de uma cultura ao longo do tempo, promovendo a previsão de safra, determinação de novas áreas de cultivo, localização da área cultivada, uso e ocupação do solo, níveis de degradação da paisagem e outras informações.

O município de Suzanápolis, localizado no Estado de São Paulo, foi escolhido para a realização do estudo deste trabalho por apresentar clima, solos e classes de declividade favoráveis ao cultivo da cana-de-açúcar. Além disso, a região caracterizase por possuir grande porcentagem de pastagens com baixas produtividades para pecuária extensiva. De 2002 em diante, essas pastagens começaram a ser substituídas pela cultura da cana-de-açúcar, em função da instalação de usinas processadoras dessa cultura e também devido à procura de uma melhor rentabilidade pelos proprietários. Esse fato mudou significativamente o espaço geográfico da região.

Atualmente, as preocupações ambientais vêm ganhando mais destaque. Buscam-se atividades ecologicamente corretas, como a proibição de queimadas e a 
delimitação das Áreas de Preservação Permanentes (APPs), com o objetivo de conservar o meio ambiente e recuperar áreas degradadas.

Por meio de ferramentas e técnicas de geoprocessamento e sensoriamento remoto, e do uso do programa computacional SPRING ${ }^{\circledR}$, versão 5.1.8, o presente trabalho tem como objetivo os seguintes itens: identificar as áreas de cultura da canade-açúcar nos anos 2003 e 2012 de acordo com as classes de declividade, avaliando o potencial de expansão dessa cultura na região e de áreas aptas à mecanização; avaliar o nível de conservação da rede de drenagem; e verificar se há cultivo de canade-açúcar em Áreas de Preservação Permanentes no município de Suzanápolis, SP.

\section{MATERIAL E MÉTODOS}

A área de estudo do trabalho foi o município de Suzanápolis, localizado na região noroeste do Estado de São Paulo, conforme mostra a Figura 1. O município pertence à microrregião de Andradina, está situado entre os paralelos $20^{\circ} 34^{\prime} 20^{\prime \prime} \mathrm{e}$ $20^{\circ} 22^{\prime} 23^{\prime \prime}$ de latitude sul e os meridianos $51^{\circ} 14^{\prime} 06^{\prime \prime}$ e $50^{\circ} 57^{\prime} 37^{\prime \prime}$ de longitude oeste. Sua população é de 3.383 habitantes e apresenta uma área total de $328,526 \mathrm{~km}^{2}$. 0 local fica cerca de 640 quilômetros da capital do Estado de São Paulo e é margeado por um grande rio, o Rio São José dos Dourados (IBGE, 2010).

Essa área é de influência do Complexo de Urubupungá, onde estão localizadas as usinas hidrelétricas de Jupiá, Ilha Solteira e Três Irmãos. O clima dessa região, classificado de acordo com o Sistema Internacional de Köeppen, é o tropical úmido, com estações chuvosas no verão e seca no inverno (Aw). A temperatura média anual é de $23,5^{\circ} \mathrm{C}$ e as precipitações médias mensais variam de $20 \mathrm{~mm}$ (agosto) a $254 \mathrm{~mm}$ (janeiro) (CENTURION, 1982).

Todos os dados geoespaciais foram inseridos em um banco de dados digital, onde se utilizou o programa SPRING/INPE, composto por imagens Landsat7/ETM+ Ortorretificada, usadas como referência para registro de imagens do satélite CBERS2B, sensor CCD e HRC, satélite LANDSAT5, sensor TM, com o objetivo de melhorar a precisão geométrica. Para delimitação correta da área de estudo, o município de Suzanápolis, SP, o limite municipal vetorizado e georreferenciados foi inserido no banco de dados. 
Figura 1- Localização da área de Estudo - Município de Suzanápolis

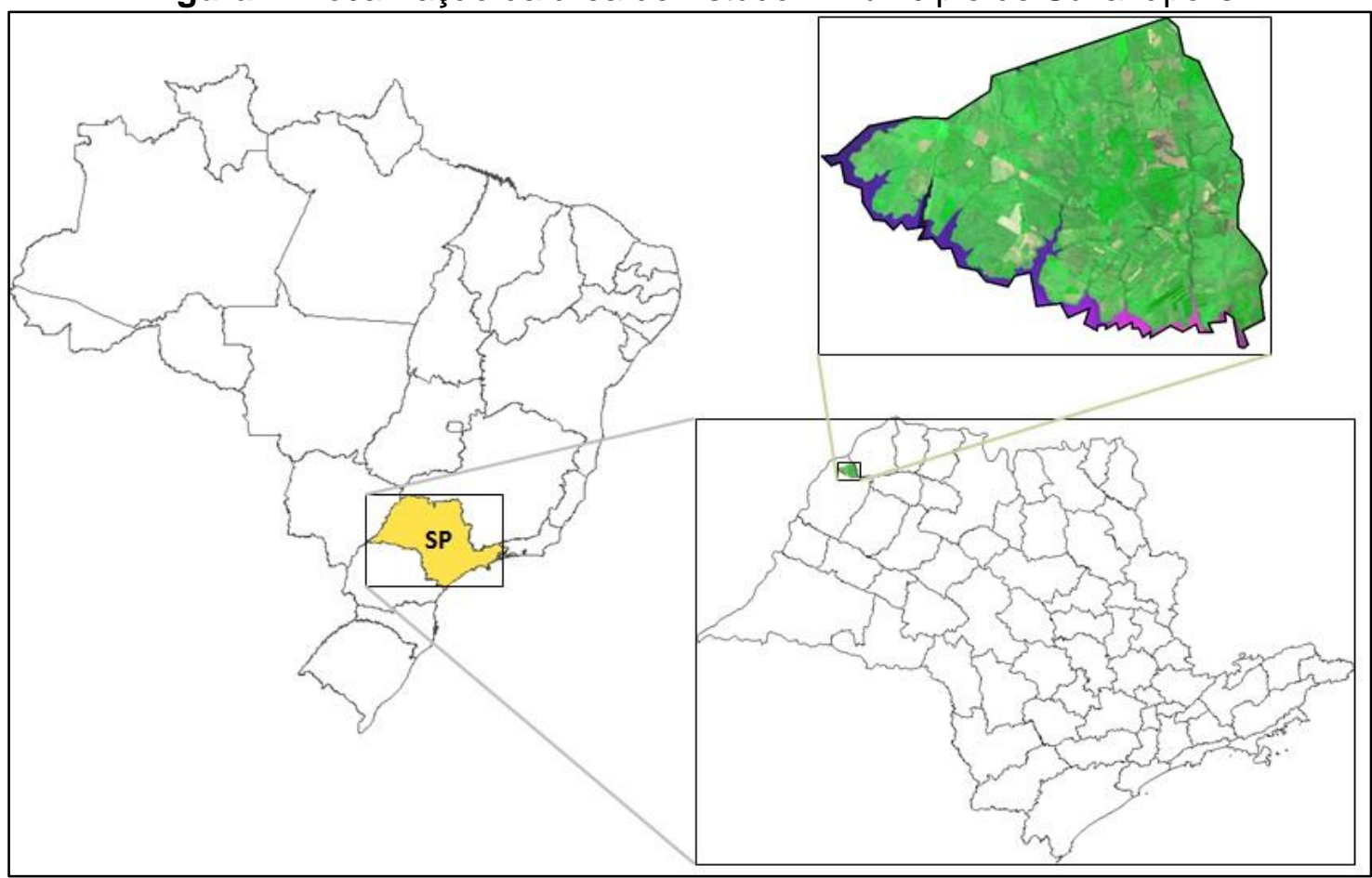

Fonte: FRANCO, 2017

Para obter melhor visualização e interpretação da área de estudo, foi realizado o processo de fusão de imagens para as cenas inseridas no banco dados, do qual foi possível obter a integração da melhor resolução espacial da banda pancromática com a melhor resolução espectral das demais bandas.

À criação do mapa de declividade e à digitalização e vetorização da rede de drenagem presente no município, utilizou-se a geração de isolinhas de grade SRTM Shuttle Radar Topography Mission, obtida através da EMBRAPA. As classes de declividade foram definidas em intervalos de $0-2 \%$; 2-5\%; 5-10\%; $10-12 \%$ e $12-45 \%$. Para a delimitação da rede hidrográfica, realizou-se a identificação de todos os canais de drenagem, foram identificadas as seguintes classes: leito seco; leito perene; represes presentes na rede. A partir dessa etapa, foi possível a identificação de nascentes e delimitação de Áreas de Preservação Permanentes (APPs), a partir da geração de mapas de distâncias, seguindo as normas de delimitação do Código Florestal e Resolução CONAMA.

Para avaliação do nível de degradação em APPs, utilizou-se a metodologia do Modelo Linear de Mistura Espectral, método inserido no software SPRING ${ }^{\circledR} /$ /NPE, necessitando de alguns ajustes em erros constatados em análises feitas por fotointerpretação.

Com o objetivo de delimitar as áreas destinadas ao cultivo da cultura de canade-açúcar, importaram-se arquivos shapefiles para o banco de dados, obtidos por 
meio do projeto Canasat/INPE, contendo informações necessárias das safras de 2003 e 2012.

Para a obtenção de resultados, utilizou-se o método de Tabulação Cruzada, dentro do próprio SPRING ${ }^{\circledR} /$ INPE, no qual foi feito o cruzamento de dados de planos de informações com o objetivo de gerar tabelas de resultados. Os parâmetros avaliados foram "Mapa declividade X Cana-de-açúcar" e "APP X Modelo Linear de Mistura Espectral”.

\section{RESULTADOS E DISCUSSÕES}

\section{A EXPANSÃO DA CANA-DE-AÇÚCAR E AS SAFRAS 2003/2004 - 2011/2012}

A expansão da cultura da cana-de-açúcar tornou-se mais intensa a partir da década de 1970, devido à crise mundial no setor do petróleo, que teve o preço aumentado internacionalmente. Sendo assim, o governo brasileiro criou o Programa Nacional do Álcool - PROÁLCOOL, com o objetivo de substituir o consumo da gasolina por álcool obtido a partir da cana-de-açúcar, em busca de uma alternativa viável para não sofrer com a crise. A partir do ano de 1980, com a baixa dos preços do petróleo e o aumento do preço do açúcar no mercado internacional, a produção de álcool tornou-se pouco vantajosa e decaiu; a produção de açúcar tornou-se mais viável para os usineiros (PROENÇA, 2008).

Segundo Silva (2009), problemas com limitações de áreas, preços altos de terras, questões ambientais e sociais estimularam a migração da cultura da cana-deaçúcar para a região noroeste do Estado de São Paulo. Já Cortez (2001) cita que o aumento da migração dessa cultura ocorre principalmente devido à legislação ambiental, que procura áreas afastadas de centro urbanos e áreas mais planas.

Segundo IEA (2012), em conjunto com a Coordenadoria de Assistência Técnica Integral (CATI), a área total do cultivo de cana no ano de 2004, obtida na EDR de Andradina, foi de 95.812 hectares. No município de Suzanápolis, o total foi de 3.550 hectares; e no Estado de São Paulo foi de 3.312.786,3 hectares. No ano de 2011, foi obtida, na EDR de Andradina, a área total de 258.751,8 hectares; 8.400 hectares no município de Suzanápolis,-e 5.841.593,5 hectares no Estado de São Paulo.

O Projeto CANASAT foi criado pelo Instituto Nacional de Pesquisas Espaciais (INPE), em conjunto com as instituições União da Indústria de Cana-de-Açúcar (UNICA), com o Centro de Estudos Avançados em Economia Aplicada (CEPEA) da Escola Superior de Agricultura Luiz de Queiroz (Esalq/USP) e com o Centro de 
Tecnologia Canavieira (CTC). O seu objetivo é determinar anualmente, com o uso de imagens de satélite e técnicas de geoprocessamento e sensoriamento remoto, a área cultivada com a cultura de cana-de-açúcar no Estado de São Paulo desde a safra 2003/2004. Esse controle é fundamental para avaliar a sustentabilidade da produção do etanol no Brasil (RUDORFF et al. 2005).

Os resultados a respeito das áreas da cultura de cana-de-açúcar no município de Suzanápolis foram obtidos pelo cruzamento de informações referentes às classes de declividade do município com os dados fornecidos pelo Canasat/INPE referentes à cultura das safras nos anos de 2003/2004 e 2011/2012. Nas Tabelas 1 e 2, foi observado que o município de Suzanápolis tinha um total de 30.363,03 hectares de áreas aptas ao cultivo de cana-de-açúcar na safra 2003/2004.

Tabela 1 - Área (ha) agricultável e com a cultura de cana-de-açúcar na safra 2003/2004 por classe de declividade em Suzanápolis, SP.

\begin{tabular}{cccccccc}
$\begin{array}{c}\text { Estágio de Cultivo da } \\
\begin{array}{c}\text { Cana-de-Açúcar Safra } \\
\text { 2003/2004 (ha) }\end{array}\end{array}$ & \multicolumn{5}{c}{ Classes de Declividade (\%) } & \multirow{2}{*}{ Total } \\
\cline { 2 - 6 } & $\mathbf{0 - 2} \%$ & $\mathbf{2 - 5} \%$ & $\mathbf{5 - 1 0 \%}$ & $\mathbf{1 0 - 1 2 \%}$ & $\mathbf{1 2 -}$ & \\
\hline Soca & 260,37 & 2118,06 & 756,90 & 6,03 & 1,71 & 3143,07 \\
\hline Reforma & 7,38 & 73,89 & 5,94 & 0,00 & 0,00 & 87,21 \\
\hline $\begin{array}{c}\text { Área ocupada com a } \\
\text { cultura de cana-de- } \\
\text { açúcar }\end{array}$ & 267,75 & 2191,95 & 762,84 & 6,03 & 1,71 & 3230,28 \\
\hline $\begin{array}{c}\text { Área agricultável sem a } \\
\text { cultura de cana-de- } \\
\text { açúcar }\end{array}$ & 2913,75 & 18171,81 & 5950,62 & 71,19 & 25,38 & 27132,75 \\
\hline \begin{tabular}{c} 
Total \\
\hline
\end{tabular} & 3181,50 & 20363,76 & 6713,46 & 77,22 & 27,09 & 30363,03 \\
\hline
\end{tabular}

Fonte: Processamento Digital de Imagens - FRANCO, 2017.

Tabela 2 - Área (\%) agricultável e com a cultura de cana-de-açúcar na safra 2003/2004 por classe de declividade em Suzanápolis, SP.

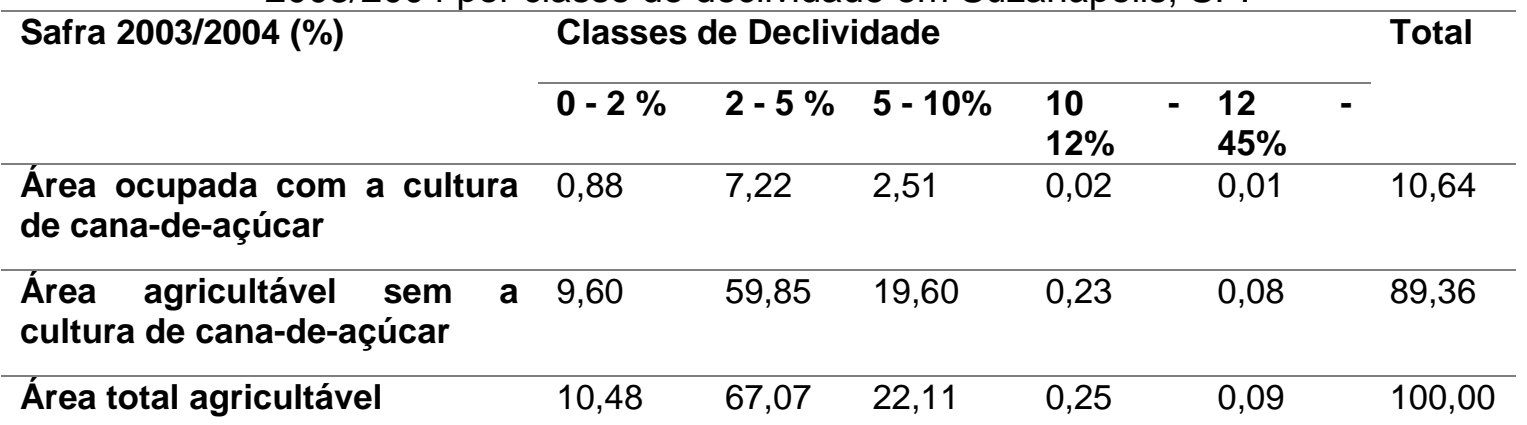

Fonte: Processamento Digital de Imagens - FRANCO, 2017.

Foram identificados, no município de Suzanápolis, 30.335,94 hectares de áreas agricultáveis com classe de até $12 \%$ de declividade, aptas às colheitas mecanizadas, 
ou seja, $99,91 \%$ da área total tem potencial para a prática da mecanização. Esses dados condizem com Cortez (2001), o qual afirma que locais com áreas mais planas favorecem o cultivo da cultura da cana-de-açúcar-

A figura 2 caracteriza as áreas de cana-de-açúcar nas diferentes classes de declividade do município.

Figura 2: Cultura da cana-de-açúcar nas classes de declividade dos solos no Município de Suzanápolis, SP - Safra 2003/2004.

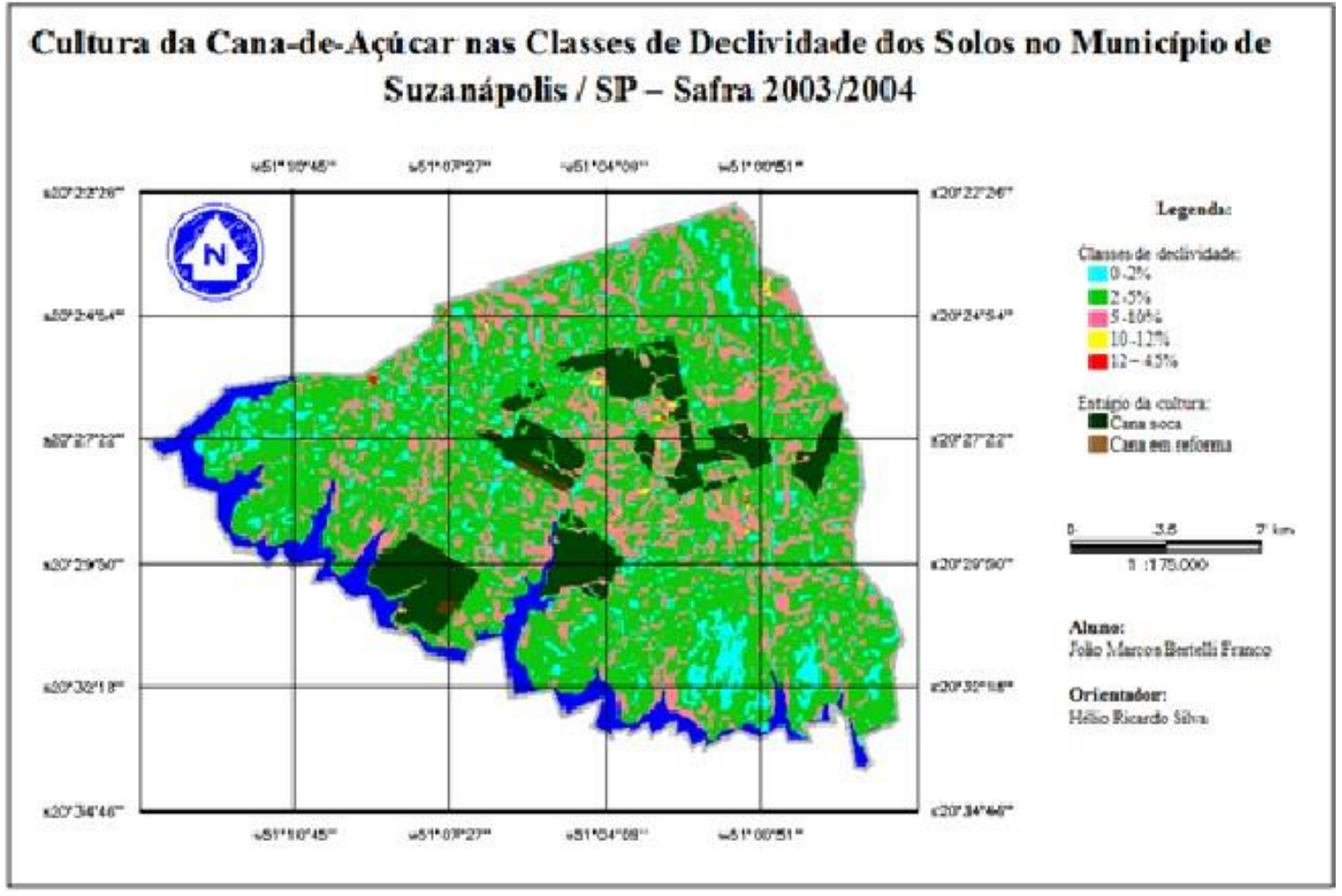

Fonte: FRANCO, 2017.

Na safra 2003/2004, a ocupação da cultura era de 3.230,28 hectares (10,64\%), na safra $2011 / 2012$ foi de $6.770,16$ hectares (22,30\%). Isso significa que, a expansão da cultura no município foi de $209,59 \%$ em nove anos. Nas Tabelas 3 e 4 , foi observado que o município de Suzanápolis teve um total de 30.363,03 hectares de áreas aptas ao cultivo de cana-de-açúcar na safra 2011/2012.

Comparando os dados das safras 2003/2004 e 2011/2012, observou-se que as áreas novas cultivadas entre esses nove anos estão sendo tratadas em classes de declividade adequadas à mecanização.

Se relacionarmos, contudo, os dados fornecidos pelo Canasat (2012), os quais informam que no município de Suzanápolis, na safra 2011/2012, o total de cana colhida com queima foi 3.382 hectares, constata-se que $49,95 \%$ das áreas com a cultura ainda não possuem mecanização. Sendo assim, segundo a Lei $n^{\circ} 11.241$ (BRASIL, 2002), junto com o Protocolo Ambiental (2007), essa região tem até 2014 
para aplicar o sistema de colheita de cana crua em uma área de aproximadamente 3382 hectares.

Tabela 3 - Área (\%) agricultável e com a cultura de cana-de-açúcar na safra 2003/2004 por classe de declividade em Suzanápolis, SP.

\begin{tabular}{|c|c|c|c|c|c|c|}
\hline \multirow[t]{3}{*}{ Safra 2011/2012 (\%) } & \multicolumn{5}{|c|}{ Classes de Declividade } & \multirow[t]{3}{*}{ Total } \\
\hline & \multirow[t]{2}{*}{$0-2 \%$} & \multirow{2}{*}{$\begin{array}{c}2-5 \\
\%\end{array}$} & \multirow[t]{2}{*}{$5-10 \%$} & \multirow{2}{*}{$\begin{array}{l}10- \\
12 \%\end{array}$} & \multirow{2}{*}{$\begin{array}{l}12- \\
45 \%\end{array}$} & \\
\hline & & & & & & \\
\hline \multicolumn{7}{|l|}{ de cana-de-açúcar } \\
\hline $\begin{array}{l}\text { Área agricultável sem a } \\
\text { cultura cana-de-açúcar }\end{array}$ & \multicolumn{5}{|c|}{ cultura cana-de-açúcar } & 77,70 \\
\hline Área total agricultável & 10,48 & 67,07 & 22,11 & 0,25 & 0,09 & 100,00 \\
\hline \multicolumn{7}{|c|}{ Fonte: Processamento Digital de Imagens 2011/2012 - FRANCO, 2017.} \\
\hline \multicolumn{7}{|c|}{$\begin{array}{c}\text { Tabela } 4 \text { - Área (ha) agricultável e com a cultura de cana-de-açúcar na safra } \\
\text { 2011/2012 por classe de declividade em Suzanápolis/SP. }\end{array}$} \\
\hline \multirow{2}{*}{$\begin{array}{l}\text { Estágio de Cultivo da } \\
\text { Cana-de-Açúcar Safra } \\
2011 / 2012 \text { (ha) }\end{array}$} & \multicolumn{5}{|c|}{ Classes de Declividade } & Total \\
\hline & $0-2 \%$ & $2-5 \%$ & $5-10 \%$ & $\begin{array}{l}10- \\
12 \%\end{array}$ & $\begin{array}{l}12- \\
45 \%\end{array}$ & \\
\hline Soca & 538,38 & 4512,69 & $\begin{array}{c}1408,6 \\
8\end{array}$ & 6,03 & 0,54 & 6466,32 \\
\hline Reforma & 13,32 & 184,05 & 96,21 & 0,00 & 0,00 & 293,58 \\
\hline Expansão & 0,00 & 9,09 & 1,17 & 0,00 & 0,00 & 10,26 \\
\hline $\begin{array}{l}\text { Área ocupada com a } \\
\text { cultura de cana-de-açúcar }\end{array}$ & 551,70 & 4705,83 & $\begin{array}{c}1506,0 \\
6\end{array}$ & 6,03 & 0,54 & 6770,16 \\
\hline $\begin{array}{l}\text { Área agricultável sem a } \\
\text { cultura de cana-de-açúcar }\end{array}$ & $\begin{array}{l}2629,8 \\
0\end{array}$ & $\begin{array}{l}15657,9 \\
3\end{array}$ & $\begin{array}{l}5207,4 \\
0\end{array}$ & 71,19 & 26,55 & $\begin{array}{c}23592,8 \\
7\end{array}$ \\
\hline Total & $\begin{array}{l}3181,5 \\
0\end{array}$ & $\begin{array}{l}20363,7 \\
6\end{array}$ & $\begin{array}{l}6713,4 \\
\quad 6\end{array}$ & 77,22 & 27,09 & $\begin{array}{l}30363,0 \\
3\end{array}$ \\
\hline
\end{tabular}

Fonte: Processamento Digital de Imagens 2011/2012 - FRANCO, 2017.

A figura 3 caracteriza as áreas de cana-de-açúcar nas diferentes classes de declividade do município.

Nas áreas de cana-de-açúcar presentes do espaço geográfico estudado, observou-se, utilizando a imagem fusionada e os dados shapefiles fornecidos pelo Canasat na safra 2011/2012, que as informações da imagem acopladas aos dados shapefiles apresentaram boa exatidão. 
Figura 3: Cultura da cana-de-açúcar nas classes de declividade dos solos no município de Suzanápolis, SP - Safra 2011/2012.

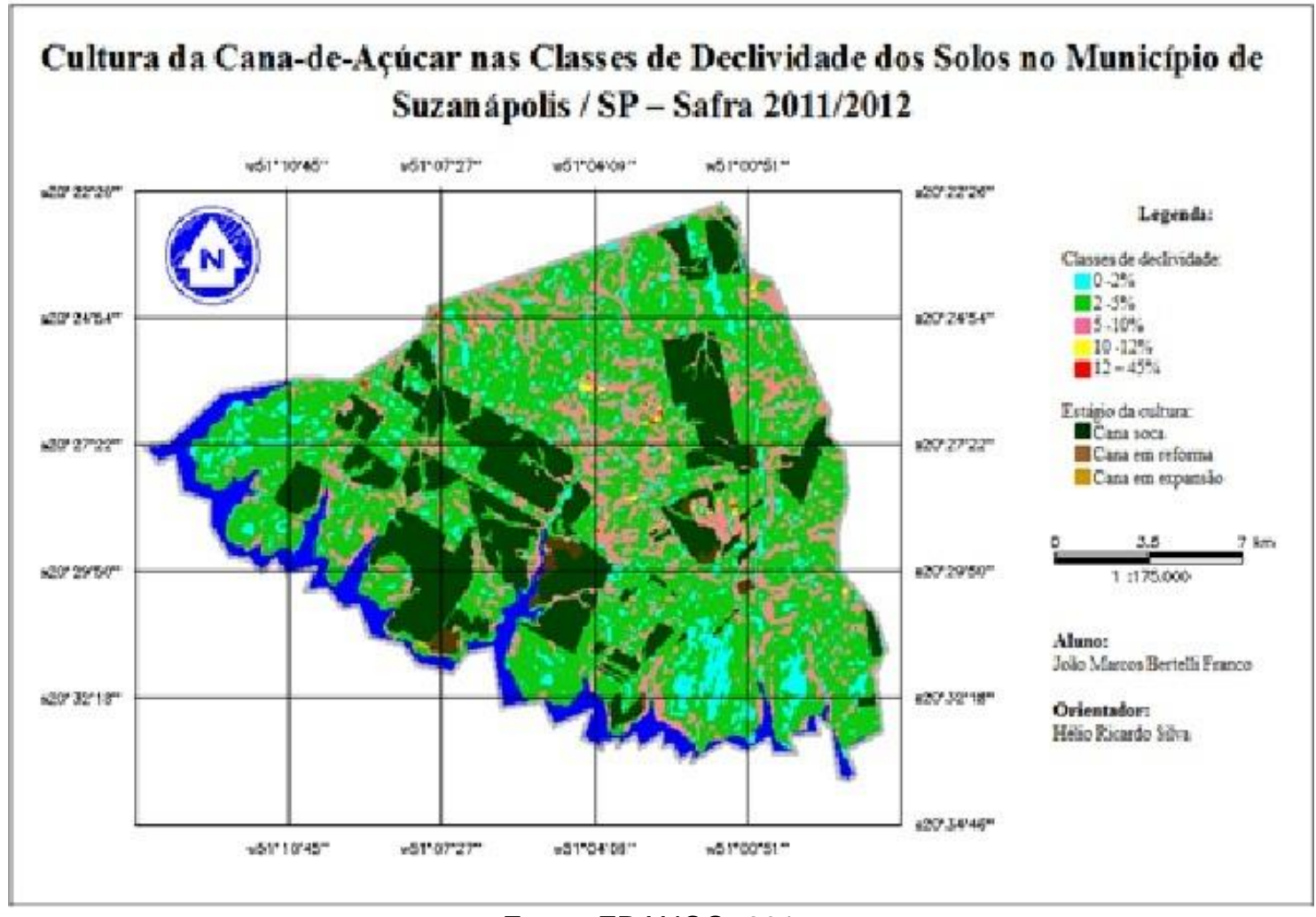

Fonte: FRANCO, 2017.

Há, no entanto, alguns locais em que o Canasat superestimou o total da área da cultura de cana-de-açúcar, contabilizando algumas Áreas de Preservação Permanente, nascentes e áreas de vegetação nativa. (Figura 4)

Figura 4: Área de Preservação Permanente: (A) Imagem CBERS fusionada mostrando a APP sem a presença da cana-de-açúcar; (B) Mapeamento do CANASAT, na mesma área recobrindo a APP.

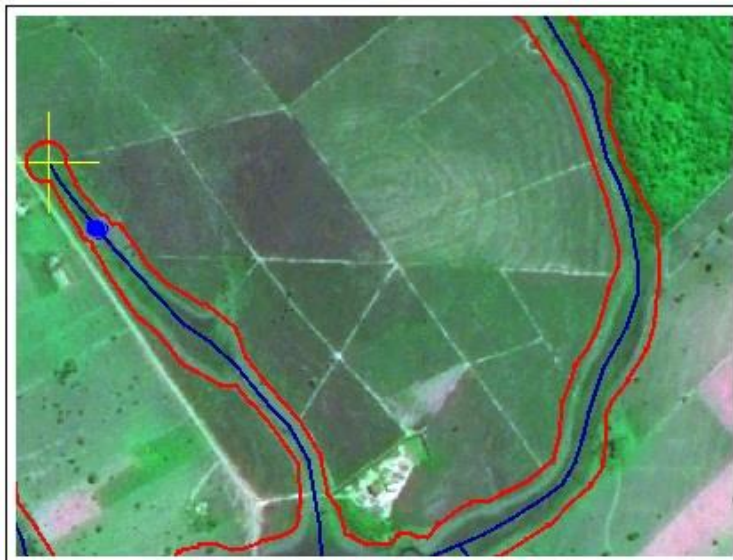

(A)

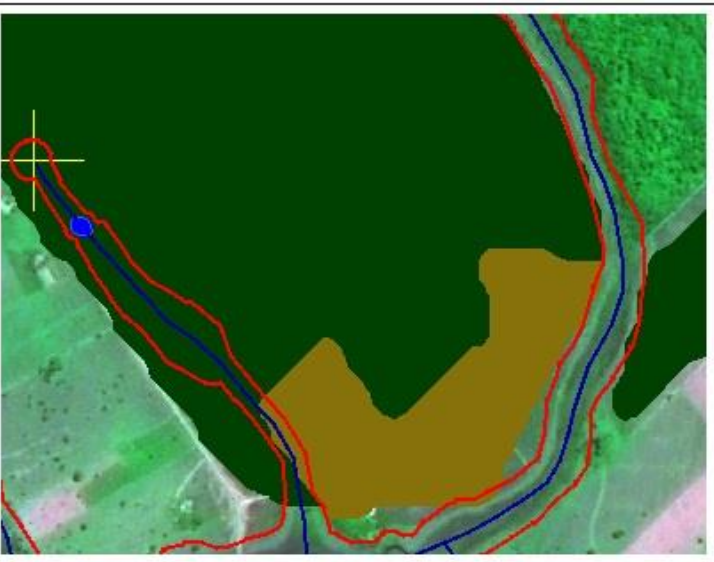

(B)

Fonte: FRANCO, 2017.

Geografia (Londrina) v. 26. n. 1. p. $104-117$, jan/jun, 2017. 
Esse erro de superestimação do Canasat também foi comentado por Palla et al. (2011) ao avaliar o potencial de expansão da cultura de cana-de-açúcar em llha Solteira, SP.

Com o cruzamento de informações das áreas de cultura de cana-de-açúcar da safra 2011/2012 com os das APPs, calculou-se que a cultura implantada em APPs foi de 63,24 hectares, ocupando 1,53\% da área total de APPs e desrespeitando a lei ambiental (Figura 5).

No entanto, há superestimação da cultura em APPs, como citado anteriormente, o que pode interferir significativamente nesses valores. Sendo assim, para uma melhor acurácia desses dados, recomenda-se a realização de campanhas de campos.

\section{Figura 5 - Área de cana-de-açúcar implantada em Áreas de Preservação Permanente}

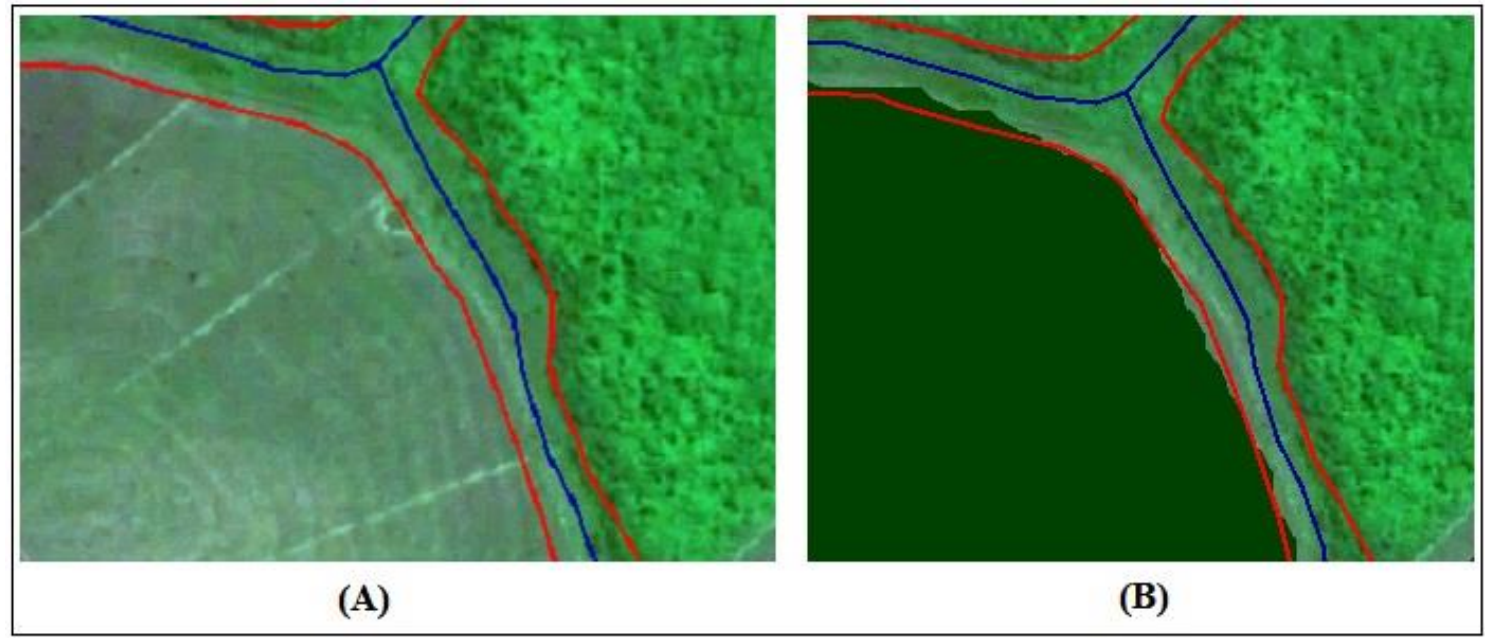

Fonte: FRANCO, 2017.

Nesse trabalho, houve a mesma tendência ao se comparar a estimativa de safras 2003/20004 e 2011/2012 fornecida pelo shapefiles do Canasat, sendo uma área de 3.230,28 hectares em 2003/20004 e uma de 6.770,16 hectares em 2011/2012, com a estimativa do Instituto de Economia Agrícola, sendo uma área de 3.550 hectares em 2003/2004 e uma de 8.400 hectares em 2011/2012. Na safra 2011/2012, ao se fazer a interpretação dos dados do Canasat, no mapa apresentado na figura 6, com as informações do limite de município de Suzanápolis e as áreas da cultura de cana-deaçúcar, teve se como uma hipótese de conclusão o fato do Canasat estimar safras apenas dentro do limite do município, enquanto o Instituto de Economia Agrícola estima safras obtidas por informações de técnicos da CATI com visitas às propriedades rurais, as quais possibilitam a identificação de áreas encontradas fora do limite municipal. 
Figura 6: Mapa da cultura de cana-de-açúcar dentro e fora do limite municipal de Suzanápolis, SP.

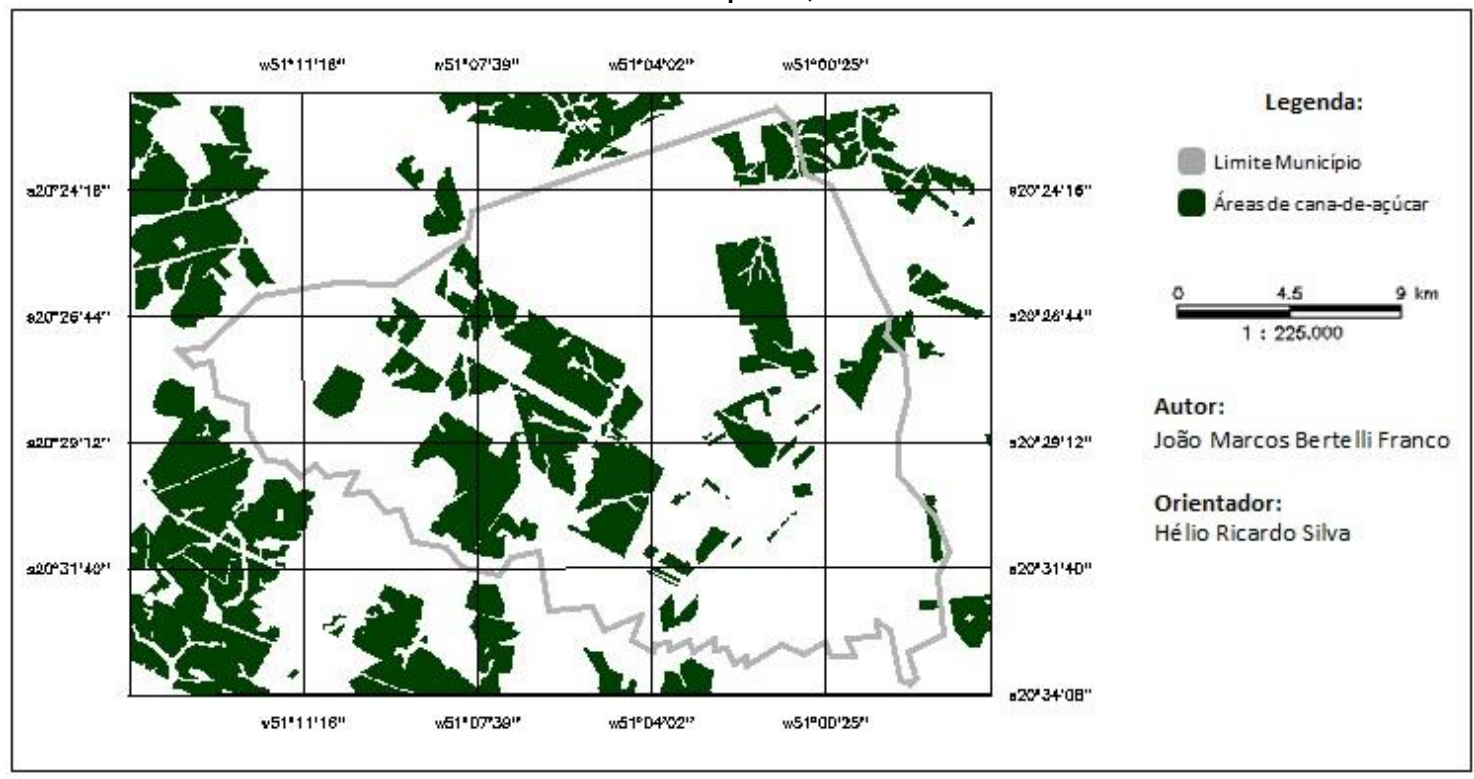

Fonte: FRANCO, 2017.

Os resultados obtidos, pela ferramenta MLME, representados na figura 7 , foram calculados pelo cruzamento de informações das Áreas de Preservação Permanentes totais do município de Suzanápolis SP, com a imagem temática final classificada pelo MLME. Os níveis de conservação adotados foram: conservado, representado por vegetação arbórea e/ou arbustiva densa; parcialmente degradado, representado por pastagens e vegetação herbácea; e degradado, representado por solo exposto e pastagens degradadas. Na tabela 6 , os valores apresentam-se em área (ha) e porcentagem.

Tabela 1: Níveis de conservação das Áreas de Preservação Permanentes da rede de drenagem do município de Suzanápolis, SP.

\begin{tabular}{lll}
\hline Estado de Conservação da APP & Área (ha) & Área (\%) \\
\hline Conservada & 1270,62 & 30,72 \\
\hline Parcialmente Degradada & 2739,15 & 66,21 \\
\hline Degradada & 127,11 & 3,07 \\
\hline Total & 4136,88 & 100,00 \\
\hline
\end{tabular}

Com bases nos dados apresentados na tabela 6, verificou-se que a Área de Preservação Permanente total do município estudado é de 4.136,88 hectares, sendo que apenas $30,72 \%$ atende à legislação ambiental e que $69,28 \%$ dessas áreas apresentam problemas ambientais. 
Figura 7: Mapa dos níveis de conservação das APPs no Município de Suzanápolis, SP.

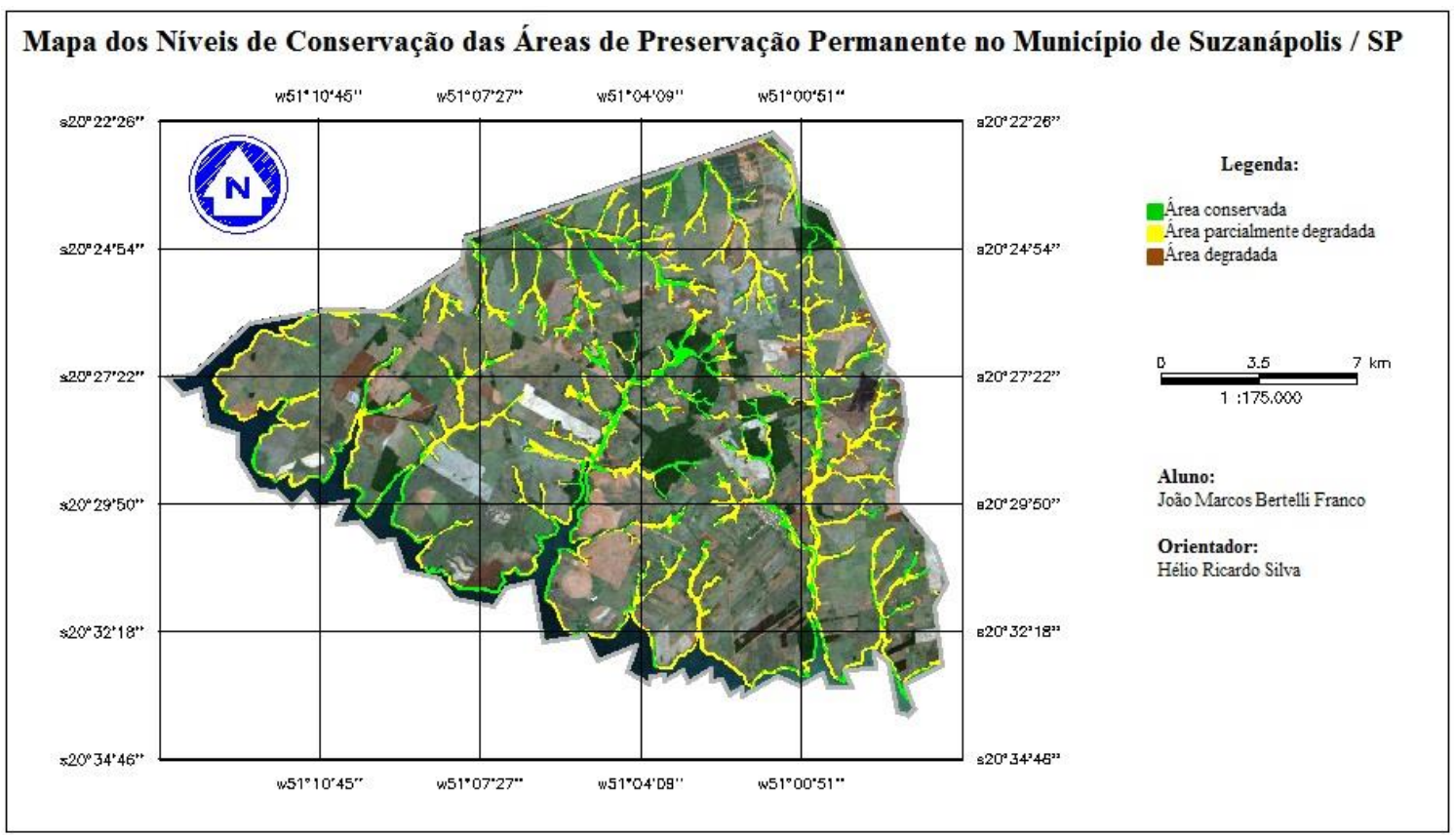

Fonte: FRANCO, 2017.

\section{CONSIDERAÇÕES FINAIS}

As técnicas de geoprocessamento utilizadas foram eficientes para uma avaliação rápida e de baixo custo da distribuição da cultura de cana-de-açúcar nas classes de declividade e nas Áreas de Preservação Permanentes no município de Suzanápolis - SP.

Entre as safras 2003/2004 e 2011/2012, as áreas cultivadas com a cultura de cana-de-açúcar tiveram uma expansão significativa, sendo que as áreas com essa cultura aumentaram em 210\%; entretanto, esse município tem um potencial de expansão de aproximadamente 23592 hectares para esse tipo de cultivo. Grande parte das áreas de plantio de cana-de-açúcar está sendo implantada em regiões com declividade de até $12 \%$, adequadas à colheita mecanizada.

Observou-se que, mesmo com a esta cultura em áreas aptas para mecanização, há um valor expressivo de áreas com queimadas, as quais representam aproximadamente de $50 \%$ do total da região. Os dados do Canasat/INPE apresentaram áreas superestimadas, onde também são mapeadas Áreas de Preservação Permanente, nascentes, canais de drenagem e áreas de vegetação nativa.

Verificou-se que há cultivo de cana-de-açúcar em algumas Áreas de Preservação Permanente, sendo necessárias campanhas de campo para verificação desses dados, devido ao fato de que algumas áreas estão superestimadas. Com o 
Modelo Linear de Mistura Espectral, constatou-se que 70\% das Áreas de Preservação Permanentes em Suzanápolis apresentaram problemas ambientais, sendo favoráveis a assoreamentos e erosões.

Atualmente a atualização das informações, utilizando os dados do Canasat/INPE, estão suspensas de forma gratuita, os dados estão paralisados nos anos de 2012/13, pois tornara-se particulares, somente podem ser acessados por compra de empresa particular, dificultando o monitoramento atual.

\section{REFERÊNCIAS}

ADAMS, J. B.; SMITH, M. O.; GILLESPIE, A. R. Remote Geochemical Analysis: Elemental and Mineralogical Composition. Cambridge: Cambridge University Press, 1993. p. 145-166.

AVERY, T. E.; BERLIN, G. L. Fundamentals of Remote Sensing and Airphoto Interpretation. 5 ed. New Jersey: Prentice Hall. 1992.

BRASIL. Lei Federal no 4.771, de 15 de setembro de 1965. Código Florestal. 1965. Disponível em: <http://www2.camara.gov.br/legin/fed/lei/1960-1969/lei-4771-15setembro-1965-369026-normaatualizada-pl.html>. Acesso em: 23 jan. 2010.

BRASIL. Resolução CONAMA no 302/2002, de 20 de março de 2002. Ministério do Meio Ambiente. Dispõe sobre os parâmetros, definições e limites de Áreas de Preservação Permanentes de reservatórios artificiais e o regime de uso do entorno. Disponível em: <http://www.mma.gov.br/conama>. Acesso em: 23 jan. 2013.

Resolução CONAMA no 303/2002, de 20 de março de 2002. Ministério do Meio Ambiente. Dispõe sobre os parâmetros, definições e limites de Áreas de Preservação Permanente. Disponível em: <http://www.mma.gov.br/conama>. Acesso em: 23 jan. 2013.

CANASAT. Monitoramento da Cana-de-açúcar via imagens de satélite: tabelas. INPE, 2012. Disponível em: http://www.dsr.inpe.br/laf/canasat/index.html. Acesso em: 16 abr. 2012.

CORTEZ, L. Mudança climática e escassez de petróleo criam oportunidade única para o Brasil. In: UNICAMP. Inovação UNICAMP: site dedicado P\&D em cana e etanol. Campinas, 2005. Disponível em:

$<$ http://www.inovacao.unicamp.br/etanol/report/entre-cortez.php $>$. Acesso em: 05 maio 2012.

CROSTA, A.P. Processamento digital de imagens de sensoriamento remoto. Campinas: Unicamp, 1992.

EMBRAPA. EMPRESA BRASILEIRA DE PESQUISA AGROPECUÁRIA. Agência de informação Embrapa: Cana-de-açúcar. Disponível em: $<$ http://www.agencia.cnptia.embrapa.br/gestor/canadeacucar/arvore/CONTAG01 682 2122006154840.html>. Acesso em: 7 maio 2012.

FERREIRA, M. E. Análise do modelo linear de mistura espectral na discriminação de fitofisionomias do Parque Nacional de Brasília (bioma Cerrado). 2003. $96 \mathrm{f}$. Dissertação (Mestrado em Geologia) - Programa de Pós-Graduação em Geografia. Universidade de Brasília (UnB), Brasília, 2003. Disponível em:

<http://www.unb.br/ig/posg/mest/Mest172/> Acesso em: 11 abr. 2012. 
IEA. INSTITUTO DE ECONOMIA AGRÍCOLA. Banco de Dados: área e produção. São Paulo, 2012. Disponível em: <http://www.iea.sp.gov.br>. Acesso em: 15 abr. 2012. LANDSAT7/ETM. University of Maryland Institute for Advanced Computer Studies. Disponível em: <http://glcf.umiacs.umd.edu/>. Acesso em: 20 abr. 2013.

MAGUIRE, D.J.; GOODCHILD, M.F.; RHIND, D.W. Geographical Information Systems: principles and applications. Nova lorque: John Wiley and Sons, 1991.

MOREIRA, M.A. Fundamentos do sensoriamento remoto e metodologias de aplicação. Viçosa, MG: Editora da UFV, 2011.

NOVO, E. M. L. M. Sensoriamento remoto: princípios e aplicações. 3. ed. São Paulo: Edgard Blucher, 2008.

Sensoriamento remoto: princípios e aplicações. 4 ed. São Paulo: Edgard Blucher, 2010. 387 p.

PALLA, G. O. Avaliação ambiental do município de Guaraçaí, SP. 2011. 67 f.

Trabalho de Conclusão de Curso (Graduação em Agronomia) - Universidade Estadual Paulista Júlio de Mesquita Filho, Campus de Ilha Solteira, UNESP, SP, 2011.

PROENÇA, E.R. Caracterização Da Produção De Cana-De-Açúcar E De Inovações Tecnológicas Adotadas Por Usinas Da Regional De Andradina (Sp). 2008. 69 f. Dissertação (Mestrado em Agronomia) - Programa de Pós-Graduação em Agronomia. - Universidade Estadual Paulista Júlio de Mesquita Filho, Campus de Ilha Solteira, UNESP, SP, 2008.

RUDORFF, B. F. T. et al. Estimativa de área plantada com cana-de-açúcar em municípios do estado de São Paulo por meio de imagens de satélites e técnicas de geoprocessamento: ano safra 2003/2004. São José dos Campos: INPE, 2004.

Imagens de satélite no mapeamento e estimativa de área de cana-deaçúcar em São Paulo: ano safra 2003/2004: Agricultura em São Paulo. vol. 52, n.1, p.21-29, 2005.

SMA. SECRETARIA DO MEIO AMBIENTE. Etanol verde: Protocolo Ambiental. São Paulo, 2012. Disponível em: <http://www.ambiente.sp.gov.br/etanolverde/zoneamento agroambiental.php>. Acesso em: 01 fev. 2012.

SILVA, I. P. F. Expansão da cultura da cana-de-açúcar e sua caracterização tecnológica no município de Birigui (SP). 2009. 60 f. Trabalho de Conclusão de Curso (Graduação em Agronomia) - Universidade Estadual Paulista Júlio de Mesquita Filho, Campus de llha Solteira, UNESP, SP, 2009.

\footnotetext{
${ }^{1}$ Professora Doutora do Curso de Licenciatura e Pós - Graduação em Geografia da Universidade Federal do Mato Grosso do Sul - Três Lagoas MS . Av. Ranulpho Marques Leal, 3484 - Distrito Industrial, Três Lagoas - MS, 79610-100 patriciaufmsgeografia@gmail.com.

2 Engenheiro Agrônomo. FEIS/UNESP. Av. Brasil Sul, 56 - Centro, Ilha Solteira - SP, 15385-000 hrsilva58@gmail.com.

${ }^{3}$ Professor Doutor do Curso de Agronomia. FEIS/UNESP - Ilha Solteira SP Av. Brasil Sul, 56 - Centro, Ilha Solteira - SP, 15385-000 hrsilva58@gmail.com.
} 